\title{
A disputa territorial e a importância econômica da Unidade de Conservação (UC) Reserva Extrativista Marinha (RESEX), em Canavieiras - BA
}

\section{The territorial dispute and economic relevance of the Conservation Unity (UC) Extractive Marine Reserve (RESEX), Canavieiras-BA}

\author{
Elder Pedreira de Souza ${ }^{1 *}$, Emerson Antônio Rocha Melo de Lucena ${ }^{2}$
}

\begin{abstract}
RESUMO
Este estudo foi desenvolvido na Reserva Extrativista Marinha (RESEX) de Canavieiras-BA, objetivando entender o conflito pelo uso do território desta Unidade de Conservação (UC) e de seu entorno, que se encontram em disputa pelos seus espaços e recursos naturais ali encontrados. Esta RESEX proporcionou ganhos a comunidade extrativista, embora tenha permitido outros usos pelo agronegócio, que atualmente convive e dialoga dentro do Conselho Deliberativo da UC. Utilizamos um jornal impresso de Canavieiras para análise do discurso de mídia. Analisamos os dados econômicos do principal município da RESEX, comparando-o com Camacã, município baiano com características socioambientais semelhantes a de Canavieiras. Os resultados encontrados demonstraram um viés unilateral tendencioso da mídia local, apresentando muitas vezes elementos constituintes de um Racismo Ambiental. Consideramos que aconteceram ganhos com a implantação desta UC, mas muito debate e pesquisa ainda serão necessários para uma convivência mais harmoniosa entre todos os usuários, setor produtivo e o Estado brasileiro.
\end{abstract}

Palavras-chave: Comunidades Tradicionais. Meio Ambiente. Disputa Territorial. Racismo ambiental.

\begin{abstract}
This is an article made at the Marine Extractivist Reserve, Canavieiras-BA. It has the objective to understand the conflicts for land and natural resources of the Conservation Unity (UC) and its surroundings. This RESEX has provided some achievements to the extractivist community, while it allowed other uses by agribusiness, which already influences the deliberative council of the UC. Using the newspaper it was possible to compare the mediatic speech between the UC city and a similar city (Camacã). The results of the research lead to think on an environmental racism hypothesis. With all the achievements of the UC, a lot of research and discussion is still needed to a good conviviality between all the UC population, government, and productive sector.
\end{abstract}

Keywords: Traditional communities. Environment. Territorial dispute. Environmental racism.

\footnotetext{
${ }^{1}$ Secretaria da Educação do Estado da Bahia - Canavieiras

* E-mail: elderpedreira@yahoo.com.br

${ }^{2}$ Universidade Estadual de Santa Cruz.
} 


\section{INTRODUÇÃO}

A Unidade de Conservação RESEX de Canavieiras nasceu do anseio da comunidade ribeirinha extrativista em ter uma área protegida mas que garantisse a continuidade de suas atividades econômicas. Requerida ao antigo Conselho Nacional de Populações Tradicionais (CNPT), no final do ano de 2001, esta unidade teve estudos biológicos, sociais e consultas públicas por 5 anos até que fosse decretada como reserva $\begin{array}{llllll}\text { federal, em } & 05 & \text { de } & \text { junho }\end{array}$ (http://www.planalto.gov.br/CCIVIL_03/Leis/L9985.htm), por Decreto sem número, abrangendo grande parte do litoral de Canavieiras, norte de Belmonte, incluindo as praias, e sul de Una, a partir das proximidades do Hotel Transamérica que fica próximo do povoado de Comandatuba, na ilha do mesmo nome.

Diferentemente da Área de Proteção Ambiental (APA), que é a unidade de conservação mais encontrada no Brasil, a RESEX é administrada por um Conselho Deliberativo gerido pelos próprios extrativist as e pelo ICMBio, participando também deste conselho segmentos públicos e empresariais, ONGs e instituições de pesquisa. Acreditamos que esta modalidade de gerenciamento possa ter despertado o descontentamento de políticos e empresários, levando a mídia a empreender uma forte campanha difamatória contra a RESEX e suas principais lideranças. Neste sentido, a análise do discurso de mídia se fará no único jornal impresso da cidade de Canavieiras, o TABU.

Vivendo em um território que por décadas tem disputado recursos naturais e agora em disputa territorial e ambiental, objetivamos entender os conflitos pelo território, pelos recursos naturais e o exercício de atividades econômicas que a despeito de utilizarem o mesmo ambiente parecem competir para exercê-las de forma excludente sem compartilhar o espaço. Objetivamoss descrever a perspectiva econômica desta luta e suas implicações na riqueza local através da evolução do PIB, e na qualidade de vida através da análise da evolução do IDHM, comparando-o com cidade que de acordo com o IBGE possua o mesmo status urbano.

Este trabalho está fundamentado em dados estatísticos coletados principalmente no Instituto Brasileiro de Geografia e Estatística (IBGE) e Superintendência de Estudos 
Econômicos e Sociais da Bahia (SEI) sobre o município de Canavieiras e alguns outros da região que apresentem características similares. Iremos analisar a evolução dos dados em período de 10 anos antes da criação da RESEX até os dias atuais.

Será realizada a descrição da luta, da evolução dos indicadores econômicos e explicaremos o fenômeno a partir do entendimento do conflito nos últimos 10 anos utilizando a bibliografia disponível, mídia e dados oficiais. Para análise e compreensão do histórico de publicações, recorremos aos trabalhos já publicados sobre a RESEX, principalmente as dissertações de mestrado apresentadas na UESC por Aguiar em $2011 \mathrm{e}$ mais preteritamente o trabalho de Ricardo Augusto Souza Machado apresentado na UFBA em 2007.

\section{A RESERVA EXTRATIVISTA DE CANAVIEIRAS: CONFLITOS E IMPORTÂNCIA}

Neste trabalho iremos abordar o conflito pelo uso dos recursos naturais na Reserva Extrativista (RESEX) de Canavieiras-BA, os discursos de mídia utilizados durante o período de implantação desta Unidade de Conservação (UC) e o empoderamento econômico da cidade e do entorno desta área protegida. Tendo nascido do anseio da comunidade extrativista em documento formalizado ao Conselho Nacional de Populações Tradicionais (CNPT), no final de 2001, somente foi criada através do Decreto SN de 05 de junho de 2006, com poligonal na figura 1, num total de 100.726,36 hectares, sendo porém, $84 \%$ de águas oceânicas.

Com uma audiência pública na cidade de Canavieiras em 30 de julho de 2003, e outra na Ilha de Barra Velha em 04 de dezembro de 2005, com estudos biológicos e sociais realizados pelo CNPT e IBAMA, a área abrange grande parte do litoral do município de Canavieiras, pequena porção do litoral sul do município de Una, e a porção ao norte da foz do Rio Jequitinhonha no município de Belmonte BA, exceto a praia.

Este ato federal está alicerçado na lei 9.985/2000 que instituiu o Sistema Nacional de Unidades de Conservação (SNUC). O Decreto de criação em seu artigo segundo assim define o objetivo da RESEX, “(...) proteger os meios de vida e a cultura da população extrativista residente na área de sua abrangência e assegurar o uso sustentável dos recursos naturais da unidade". 
A partir da possibilidade de criação da RESEX, poucos meses antes de junho de 2006 e por vários anos após o ato oficial, a classe política e o setor desenvolvimentista da região empreendem forte campanha na opinião pública para tentar convencer a população local de que esta Unidade de Conservação geraria enormes prejuízos a cidade, limitando as atividades econômicas e impedindo a geração de novos empregos.

Figura 1: Carta de Localização dos municípios de Una Canavieiras e Belmonte que compõem esta Unidade de Conservação (em verde) no Estado da Bahia.

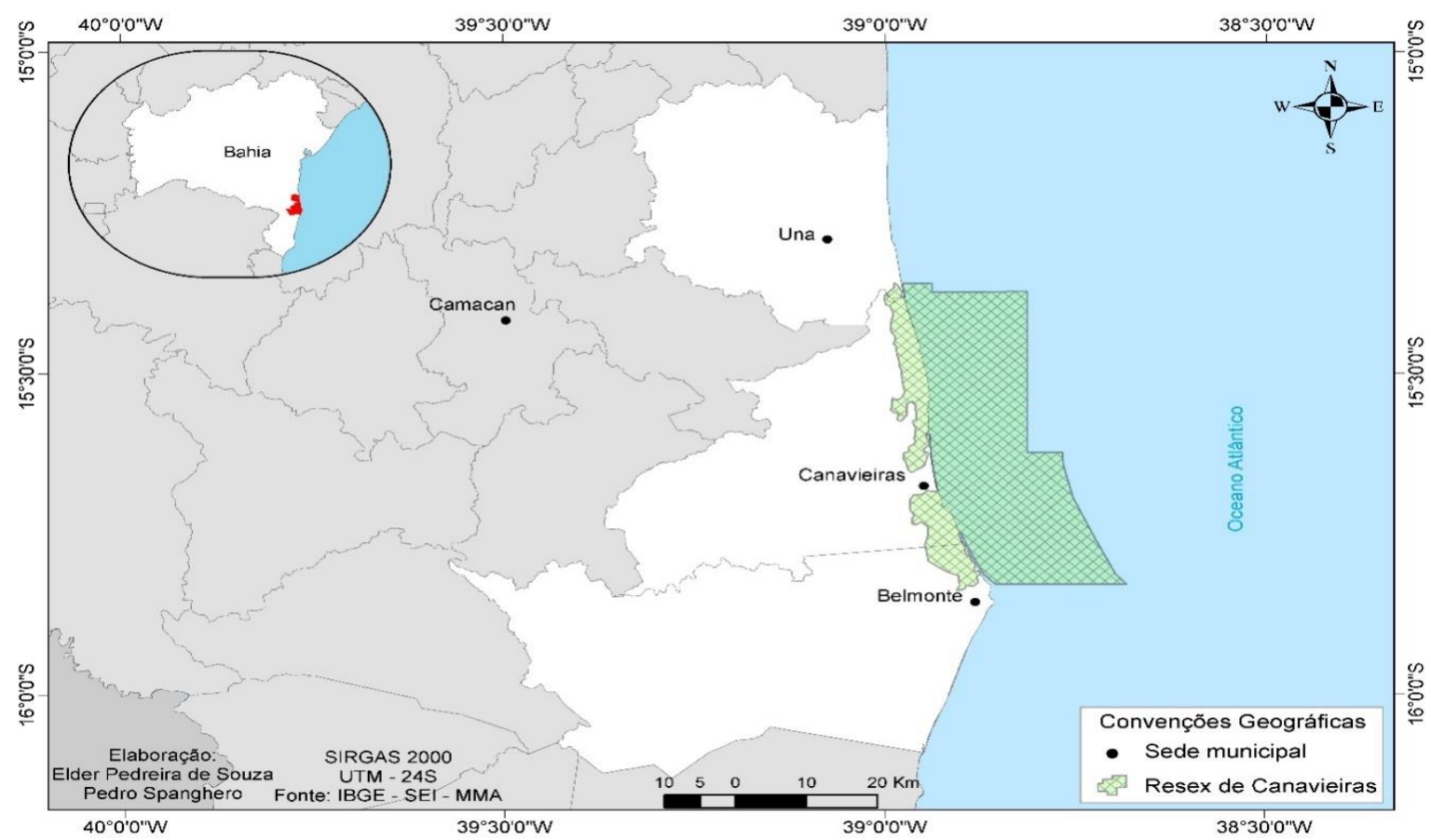

FONTE: Base de dados IBGE / SEI e MMA. Elaboração do primeiro autor.

Entendemos que a satisfação das necessidades das populações em geral é uma questão estratégica para o Estado, mas principalmente para as próprias comunidades. Satisfazer estas necessidades utilizando os recursos naturais tem sido um desafio desde tempos imemoriais. Atualmente porém, com o advento dos transportes rápidos e eficientes, as sociedades habitam os espaços sem necessidade de depender dos recursos que estão muito próximos, como água, alimentos e produtos de uso em geral. A dependência se dá muito mais para pessoas que não possuem muitos recursos materiais para adquirir o que foi produzido em longas distâncias. Ter acesso ao trabalho, direito universal, sem se deslocar e mantendo suas características tradicionais e seu modo de vida, pressupõe o desafio de continuar no ambiente que muitas vezes é requerido pelo capital especulativo, pelo sistema agrícola ou empreendedores de qualquer natureza. $\mathrm{O}$ 
uso do território por populações tradicionais já é consagrado no direito, e quando fazemos nosso trabalho nos vem algumas questões que precisam ser respondidas: A quem serve o progresso? O que é o desenvolvimento? É melhor manter a qualidade de vida e a qualidade do ambiente ou se inserir no mercado de consumo e produção? Se abdicarmos da qualidade de vida ou do ambiente para gerarmos emprego, aqueles que produzem com base na tradição terão lugar neste novo mundo?

Nos propomos a discutir estas questões para entender se os conflitos no território RESEX e entorno visam melhorar a qualidade de vida da população em geral ou empoderamento de proprietários de terra. Será justo modificar um modo de produção sustentável e tradicional para que o capital possa dispor deste espaço e decidir quem deve consumi-lo? As experiências de espaços "consumidos" pelo turismo, conforme Milton Santos (1985) ou alterados pelos parques industriais precisam ser avaliadas para que possamos decidir se as populações tradicionais têm condições de se manter e gerar um excedente de produção para girar a roda da economia.

Imaginamos que a criação desta UC tenha proporcionado algum ganho para a população alvo das políticas públicas decorrentes da criação desta RESEX, entretanto é necessário mensurar o alcance dos benefícios para outras parcelas da população que indiretamente possam ter sido alcançadas pelo incremento nas atividades que dependem dos recursos protegidos agora de forma mais intensa.

\section{MEIO AMBIENTE: DE TERRA DE NINGUÉM À TERRA DE DIREITOS}

A criação de Unidades de Conservação no Brasil, é uma prática que data de muitas décadas tendo sido criada em 1937 a primeira UC, o Parque Nacional do Itatiaia no Estado do Rio de Janeiro (DIAS, 2004). A partir de 1988 após a redemocratização do Brasil e a vigência da Nova Constituição, o país passa a discutir mais fortemente as demandas ambientais, que ficaram consagradas no Art. 225 em que se garante ao cidadão o direito a um meio ambiente saudável e equilibrado (BRASIL, 1988).

Posteriormente, com a Conferência das Nações Unidas sobre o Meio Ambiente e o Desenvolvimento, realizada no Rio de Janeiro em junho de 1992, os povos tradicionais ganham destaque no cenário político brasileiro, consagrando-se estes direitos difusos na 
Lei 9.985/2000, conhecida também como Sistema Nacional de Unidades de Conservação (SNUC).

Tomando como base a Lei 9.985/2000 e após mais de quatro anos de luta, organização e empenho dos desfensores da RESEX, finalmente o Governo Federal edita o Decreto S/N, de 06 de junho de 2006, criando a Reserva Extrativista de Canavieiras. Esta Lei prevê duas categorias de Unidades de Conservação (UC): as UC integrais e as UC sustentáveis. Esta última categoria, na qual está enquadrada a RESEX, possibilita que se proteja o Meio Ambiente, mas também permite usos sustentáveis para a área protegida. Inovação considerável nesta lei foi o reconhecimento ao direito dos povos tradicionais, com a possibilidade de criação de área protegida com a permanência de populações que ao longo da história fizeram usos sustentáveis do ambiente protegido. Referindo-se a estas populações, assim se manifesta Arruda (1999):

\section{(...) as populações alijadas dos núcleos dinâmicos da economia nacional, ao longo de toda a história do Brasil, adotaram o modelo da cultura rústica, refugiando-se nos espaços menos povoados, onde a terra e os recursos naturais ainda eram abundantes, possibilitando sua sobrevivência e a reprodução desse modelo sociocultural de ocupação do espaço e exploração dos recursos naturais, com inúmeros variantes locais determinados pela especificidade ambiental e histórica das comunidades que neles persistem (ARRUDA, 1999, p. 82).}

A presença do homem em determinados espaços, leva a assumir feições distintas, por precisar dominá-los e depender deste domínio para sua sobrevivência. É no espaço que existe a luta para transformá-lo em território, levando-o a assumir novas feições e chegar ao que, segundo Santos (1997), é definido: “como conjunto de sistemas de objetos e sistemas de ação, que formam o espaço de modo, indissociável, solidário e contraditório".

Nesta análise o espaço é formado por conjuntos ou sistemas que convivem e lutam para estabelecer seu domínio e usufruir benefícios econômicos. Estas relações, nem sempre harmônicas tendem a consumir o espaço e consumir o capital natural que é indispensável para o exercício da atividade, principalmente das populações mais tradicionais.

Nas relações entre os diversos grupos que disputam o território aparecem conflitos, pois a territorialidade original, exercida historicamente precisa, segundo os desenvolvimentistas, ser substituída por novas relações de poder, em que os grupos com 
maior capital financeiro e apoio político ditam regras e políticas públicas. Se faz necessário entender a função da população no domínio do território e o interesse de empresários principalmente do agronegócio e de setores do turismo em dificultar o acesso e usos desses locais de trabalho e moradia para exercer o poder, e assim delimitar este território ao sabor das conveniências, processo previsto por Raffestin (1993):

Ao se apropriar de um espaço, concreta ou abstratamente (por exemplo, pela representação), o ator "territorializa" o espaço. [...] O território, nessa perspectiva, é um espaço onde se projetou um trabalho, seja energia e informação, e que, por consequência, revela relações marcadas pelo poder (RAFFESTIN, 1993, p. 143).

O poder a que Raffestin nos remete no nosso estudo esteve exercido pela pressão da mídia que produzia "fakes" para formar uma opinião negativa na população e tentar deixa-la contrária aos objetivos planejados para conservação do ambiente e manutenção de uma população que sempre esteve integrada naquele "locus" como parte de sua vida.

Durante o processo 02006.00.2618-2001/79 para criação da RESEX os segmentos públicos, como Câmara de Vereadores, Câmara de Diretores Logistas (CDL), Maçonaria entre outros se manifestaram favoravelmente à sua criação. Porém, após o Decreto Presidencial, os fazendeiros de camarão, e especuladores se dizendo representantes do segmento turístico entraram em disputa pelo uso do território. Esta prática parece ter a mesma característica das lutas por espaços da mesma natureza em outros estados, em que se utilizaram de estratégias idênticas, conforme Lima (2018), ao tratar de processos de criação de outras RESEX no Estado do Ceará:

\footnotetext{
Um empresário cearense, possuidor de uma casa na vizinhança, proprietário de uma rede de ensino em Fortaleza, entrou com uma ação na justiça reivindicando judicialmente 315 hectares da sua área territorial, passando a atuar junto à comunidade para provocar um processo de divisão entre os moradores. Ao mesmo tempo que estabelecia práticas assistencialistas, com promessas de construção de um posto de saúde, doação de ambulância e distribuição de cestas básicas, divulgou junto a uma parte dos moradores que a criação da RESEX significaria perdas para a comunidade (LIMA, 2017, p. 187).
}

Percebe-se, a partir da comparação das experiências de criação das RESEX tanto no Estado da Bahia como no Estado do Ceará, que a forma de dificultar o acesso das comunidades tradicionais a estes territórios, é uma campanha de classe, tendo mesmo elementos muito parecidos nos dois espaços como o slogan usado no Ceará para se opor às RESEX "Natureza SIM, reserva Não!" enquanto em Canavieiras Bahia, o slogan usado foi “Natureza SIM, Resex Não!”. Inúmeras outras estratégias foram coincidentes nestes 
espaços, como ações fundiárias, criação de animais de grande porte, limitação de acessos, dentre outros.

\section{MATERIAL E MÉTODOS}

Este trabalho se caracteriza como uma pesquisa qualitativa do tipo Análise Documental (AD), com interpretação de dados, geração de gráficos e tabelas que sirvam para demonstrar a importância econômica do recurso natural para as populações tradicionais e para a comunidade do seu entorno. Segundo Minayo (1994, p. 21) uma pesquisa qualitativa “[...] trabalha com o universo de significados, motivos, aspirações, crenças, valores e, o que corresponde a um espaço atitudes mais profundo das relações, dos processos e dos fenômenos que não podem ser reduzidos à operacionalização de variáveis”. Para Bardin (1977), a AD é naturalmente feita atravé da análise de conteúdo, para qual essa autora apresenta metodologia bastante organizada para o entendimento do conteúdo das mensagens e textos dos documentos a serem selecionados, como por exemplo, um jornal.

Este trabalho foi organizado e desenvolvido em duas partes: a primeira, uma Análise Documental (AD), e a segunda, por meio da Análise do Discurso, concluindo com a apresentação das mudanças que esta Unidade de Conservação está proporcionando para a melhoria da qualidade de vida e economia local. Os resultados apresentados a seguir estão organizados em nove subtópicos sequenciados.

\section{RESULTADOS E DISCUSSÃO}

\section{Discurso hegemônico e de sua mídia}

Tendo sido decretada em 06 de junho de 2006, esta RESEX contou, durante seu processo de estudos para criação, com o apoio de diversos setores da Sociedade Civil organizada, como Maçonaria, CDL, Câmara de vereadores, Colônia Z 20 dos Pescadores de Canavieiras, entre outras. Porém, em 04 de dezembro de 2005, após a terceira audiência pública que ocorreu na Comunidade de Barra Velha, o pólo produtor de camarões e em seguida a Prefeitura Municipal começaram a fazer a fazer oposição e investir pesadamente nos meios de comunicação para convencer a população de que a 
RESEX representava um retrocesso econômico para o município. A prefeitura que se manifestara favorável por escrito e depois em discurso do prefeito na audiência pública de Barra Velha, passou a cobrar de seus funcionários que assinassem abaixo assinado contra a RESEX, e se engajou em uma grande passeata liberando os funcionários para faltar ao serviço, se estes se engajassem de forma ativa e presente ao "Movimento Natureza sim RESEX não”.

Após a criação da Reserva Extrativista Marinha de Canavieiras, em julho de 2006, o servidor do IBAMA designado para chefiá-la (DOU) e fazer sua instalação formal, foi o Sr. Geraldo Machado Pereira. Enfrentando forte oposição dos segmentos políticos, do polo de carcinicultura e da comunidade germânica. Geraldo Preireira que tinha um perfil de fiscal do IBAMA, devido às diversas operações que realizara, acabou sendo substituído. Na edição de primeira e segunda quinzenas de janeiro de 2008, o Tabu divulga que Geraldo Pereira é substituído por Sérgio Freitas. Este último, chegando com jeito conciliador, devido pincipalmente a sua vivência em trabalhos de organização política e comunitária na Igreja Católica, tendo inclusive trabalhado com o bispo espanhol D. Pedro Casaldáliga. De fácil relacionamento com a comunidade extrativista e buscando apoio na comunidade Canavieirense, ele após idas e vindas, consegue instalar, em Ilhéus, no auditório da CEPLAC, devido as fortes ameaças, o Conselho Deliberativo da RESEX de Canavieiras. Publicada na portaria de 04 de setembro de 2009, este órgão é na prática quem administraria a UC, possuindo como chefe e coordenador dos trabalhos, um analista ambiental de carreira do ICMBio.

\section{A imprensa escrita em Canavieiras}

A cidade de Canavieiras convive, desde fins do século XIX com opiniões manifestadas por escrito em papel, principalmente por meio de jornais. Ao todo, já circularam mais de 30 jornais na cidade de Canavieiras. No começo do Século XX chegou a existir ao mesmo tempo 5 jornais impressos. Em 1968, um grupo de intelectuais liderados por Tyrone Perrucho se reuniu e criou uma revista que alguns meses depois passou a circular mensalmente e em seguida com frequência quinzenal. Dedicava-se a publicar notícias da cidade e vizinhança, com destaque para política, artigos de opinião contos, poesias e crônicas. Enfim, foi uma revista em formato de jornal. Durante décadas foi publicado quinzenalmente, porém nos dois últimos anos saiu apenas em papel, embora 
já estivesse sendo publicado na versão online desde 2005, como tabu online, até que saiu do ar em abril de 2018, junto com a última edição impressa. A partir de maio de 2018, passou a sair como um blog hospedado em outro sítio virtual, mas cujo domínio continuou sendo "tabuonline.com.br".

O proprietário do jornal, o Sr.Tyrone Perrucho, foi muito gentil em nos atender ao pedido de vista no arquivo do Jornal e conversou conosco sobre os últimos 50 anos do TABU.Fizemos uma análise detalhada de cinco dos últimos 10 anos em que o único jornal impresso estava sendo publicado. Em abril de 2018, foi a última vez que saiu uma edição impressa, exatamente no mês em que completou 50 anos de existência.

\section{Estratégias adotadas pelo Jornal Tabu}

Observamos que o movimento de oposição à RESEX sempre se pautou por colocar esta UC como uma construção de pequeno grupo, muitas vezes denominados de "ecochatos" e até "eco-aloprados" ambientais (Jornal TABU Canavieiras BA, p. 14, jan. 2008). Em Belmonte, cidade vizinha também abrangida pela RESEX, o jornal informava que apenas os funcionários do ICMBio defendem a RESEX afirmando ser construção de um coletivo de canavieirenses, mas que toda a população de Canavieiras e região a rejeitariam. Em março de 2008 o TABU credita a Sérgio Freitas a frase "RESEX será implantada de qualquer jeito". Nessa mesma edição, na página 6, o título é: "IBAMA volta à carga com RESEX que o povo não pediu e não aceita”. Nesta mesma página: "Fraude com feijoada, bebidas e pagode".

Em abril de 2008, a página 5 do mesmo jornal informa que a RESEX iria beneficiar mil extrativistas, mas iria contrariar mais de 30 mil habitantes. Notemos ainda que, o dado usado pelo IBAMA para a criação da RESEX é que ela ao beneficiar mil famílias, o jornal se apropria desta informação argumentando que a reserva criada geraria um prejuízo para o restante da população, incentivando o divisionismo na população local.

Atentemos para o fato que em toda classe, a quantidade de trabalhadores formalizados não é de 100 \%, e somente a Colônia Z 20 dos Pescadores de Canavieiras, tinha mais de 1.100 membros cadastrados neste ano. Outra tentativa de confundir a opinião pública se dá na primeira quinzena de 2008, página 2, quando o Jornal o Tabu, 
informa que 95 \% da população não quer a RESEX. Sem mencionar a origem da pesquisa, o texto não explica quem a fez ou quem a financiou, demonstrando o caráter tendencioso dessa informação.Sendo assim, constata-se a necessidade de um trabalho de Educação Emancipatória ou de Educação Ambiental crítica, principalmente nos municípios que abrangem a RESEX de Canavieiras e seu entorno, o que dialoga com o que é proposto por Manzochi \& Sansolo (1995), os quais mencionam a importância de trabalhos educacionais numa perspectiva emancipatória, a qual não se resume apenas ao acúmulo de informações, mas objetiva-se em dar condições através do acesso a diferentes informações e visões de mundo, afim de que os educandos/cidadãos tenham uma formação que vislumbre sua capacitação para uma decisão autônoma.

\section{Demonstração da opinião da população}

Em 2007, a Prefeitura Municipal de Canavieiras estava com todo seu foco na negação da RESEX. "Convidando" funcionários a se manifestarem, vestirem a camisa do movimento "Natureza sim, RESEX não", decretando feriado para passeata e usando de sua influência para conseguir patrocínios aos projetos dos setores contrários à RESEX, uma atitude no mínimo contraditória, visto que a esta prefeitura participou e se manifestou favorável ao processo 02006.00.2618-2001/ IBAMA/CNPT para criação desta Unidade de Conservação.

\section{Difamar lideranças favoráveis à RESEX}

No processo de criação da RESEX, vários estudos foram realizados, e uma ONG, o Centro de Estudos Sócio Ambientais (PANGEA), de Salvador - BA, conduziu um estudo financiado pelo FNMA (Fundo Nacional de Meio Ambiente) em que se concluiu pela necessidade de criação desta UC. Na primeira quinzena de janeiro de 2008, o jornal faz uma matéria repercutindo uma denúncia de desvio de recursos pelo PANGEA de uma cooperativa de badameiros em Feira de Santana - BA. A matéria termina informando que a Câmara de Vereadores local vai convidar a instituição para explicar as denúncias de Feira de Santana e as fraudes que teria cometido na elaboração do projeto da RESEX.

“Eco-aloprados querem miséria social". Na primeira quinzena de janeiro de 2008, o mesmo jornal TABU tentou falar em desenvolvimento sustentável e citou a Declaração de Estocolmo e a Conferência Mundial do Meio Ambiente. A matéria de poucas linhas 
termina concluindo que: os "eco-aloprados" querem implantar um regime de miséria social em Canavieiras.

Os servidores federais que chefiaram a RESEX foram nos primeiros anos sempre massacrados pelo Jornal TABU, o primeiro, Geraldo Pereira era tratado como pessoa drogada e que dirigia em alta velocidade pela cidade. Um dos chefes, da RESEX, Sérgio Freitas, ao chegar na cidade já foi contemplado com a primeira página em que dizia: "RESEX será implantada de qualquer jeito". Pessoa de fácil convívio, Sérgio logo se integrou a comunidade e participava de eventos na cidade, inclusive fazendo parte de um grupo que jogava futebol semanalmente. Por conta desta prática esportiva, ele foi conduzido pela Polícia Militar à Delegacia de Polícia local sob a alegação de estar dirigindo alcoolizado após um desses momentos de lazer. Não se comprovou o uso de álcool e mesmo assim, por precaução ele deixou a Delegacia de Polícia em outro veículo, mas foi acusado pelo jornal de ter dado "carteirada", ameaçado a polícia e saído da delegacia bêbado dirigindo seu veículo. Moveu ação judicial contra o jornal e saiu vitorioso, tendo conseguido seis meses de publicação gratuita para publicar matérias favoráveis à RESEX.

\section{Falácias repetidas mil vezes}

Empresas de Carcinicultura geram muitos empregos e não degradam o meio ambiente. Este era o "mantra" repetido pelo jornal local. Ignorando as pesquisas, as audiências públicas e o processo que tramitou por 5 anos, a imprensa local sempre ignorou que mais de 1.100 pescadores e suas famílias estavam em vias de serem beneficiadas, contra os 360 empregos (página 8, da edição de 06-02-2006), que divulgavam estar existindo nas fazendas do agronegócio, principal setor econômico interessado no combate à RESEX.

\footnotetext{
“(...) estudos divulgados pelo Banco do Nordeste, dão conta de que esta atividade é uma excelente opção para o desenvolvimento da região nordeste do Brasil. Em Canavieiras, com cerca de mil ha de tanques, já existem 360 empregos diretos" (TABU, 2006).
}

Ainda que a Prefeitura, e setores da sociedade civil tivessem se manifestado favoravelmente, era objetivo deste jornal local demonstrar para a opinião pública que houvera fraude, que as pessoas não sabiam o que falavam ou assinavam, demonstrando um caráter tendencioso das informações publicadas. 


\section{Notícias publicadas sobre a RESEX sem mencioná-la}

Em março de 2006 o jornal noticiou o acontecimento do Primeiro Festival de Moquecas realizado pela Associação de Pescadores e Marisqueiras da Atalaia (APEMA), num sábado de carnaval daquele ano. Os 26 tipos de moqueca foram elogiados pelos presentes e foi lembrado o amplo comparecimento da população local, da importância como evento turístico e do apoio do comércio local com patrocínios, mas não informa que o promotor do evento estava trabalhando diretamente para o sucesso da RESEX.

\section{Menções subliminares}

Mesmo quando se noticiavam informações do meio social, como na primeira quinzena de janeiro de 2008, TABU citava:

"Edmar participou de pescarias no Rio Madeira onde aproveitou para visitar uma RESEX no Amazonas e constatar que esse tipo de Unidade de Conservação é inadequada para regiões desenvolvidas como a nossa".

Afinal, informações com este viés demonstram o caráter político ideológico "anti - RESEX". Nesta mesma edição uma matéria ao mencionar que foi decidido por uma auditoria para analisar fraudes no processo de criação da RESEX, informa que mesmo os imóveis localizados fora da área protegida estariam desvalorizados.

Na primeira página do jornal em março de 2008, pequena nota, conforme figura 2 informa: "Polícia pega traficantes e funcionários do Ibama" A matéria trata de dois fatos distintos, que apesar de não estarem conectados pelo jornal, são tratados na mesma matéria, gerando uma informação que tem uma conotação evidente de criminalizar o órgão ambiental e impactar negativamente sua imagem frente a população local. Lembremos que possivelmente seria um crime de drogas ocorrido na cidade, noticiado com um suposto crime que teria ocorrido há mais de $350 \mathrm{~km}$ de distância. 
Figura 2: Jornal TABU de Canavieiras BA, em edição da $1^{\text {a }}$ quinzena de março 2008.

\section{Polícia pega traficantes e funcionários do lbaìna}

Uma quadrilha que tinha uma importante participação no tráfico de drogas em nossa cidade teve seus cinco membros presos em flagrante. No ato da prisāo, comandada pelo delegado Marcos Maia, eles preparavam 2 mil papelotes de crack.

Em Teixeira de Freitas, dois funcionários do lbama foram presos pela Polícia Federal quando recebiam dinheiro de uma empresa para liberar um aterro sanitário irregular e veículos apreendidos. Pág. 7.

FONTE: Dados da pesquisa.

\section{Pobreza ou desenvolvimento?}

A região em que se insere o município de Canavieiras, teve um período de grandeza econômica a partir da cultura cacaueira se firmando em um grande território, a noção do que Adonias Filho denominou "Civilização do Cacau". Até meados da década de 1980 era grande a atividade econômica baseada em um produto destinado a exportação e ao atendimento de pequenas indústrias de moagem entre Ilhéus e Itabuna. Este era porém um desenvolvimento desigual (RIBEIRO JUNIOR, 2014) com a sociedade regional se caracterizando por extratos nitidamente diferenciados com a base da pirâmide social formada por trabalhadores analfabetos e em regime de semi-escravidão. O IBGE em 1991 registrou um Índice de Desenvolvimento Humano Municipal (IDHM) abaixo de 0,320 para Canavieiras e entorno, como demonstramos na figura 3.

Nas proximidades da atual RESEX, estamos comparando social e economicamente com o município de Camacan, por ser um município que existe desde que o cacau contava entre as grandes riquezas da Bahia, somado ao fato de que o IBGE ao avaliar a qualidade de vida de um lugar, conclui que quanto maior o tamanho, mais se ofertam serviços, lazer, comércio e emprego, com o Índice de Desenvolvimento Humano Municipal (IDHM), sendo portanto diretamente proporcional ao tamanho da população. 
Figura 3: Gráfico com evolução do IDHM na Bahia e nos municípios pesquisados.

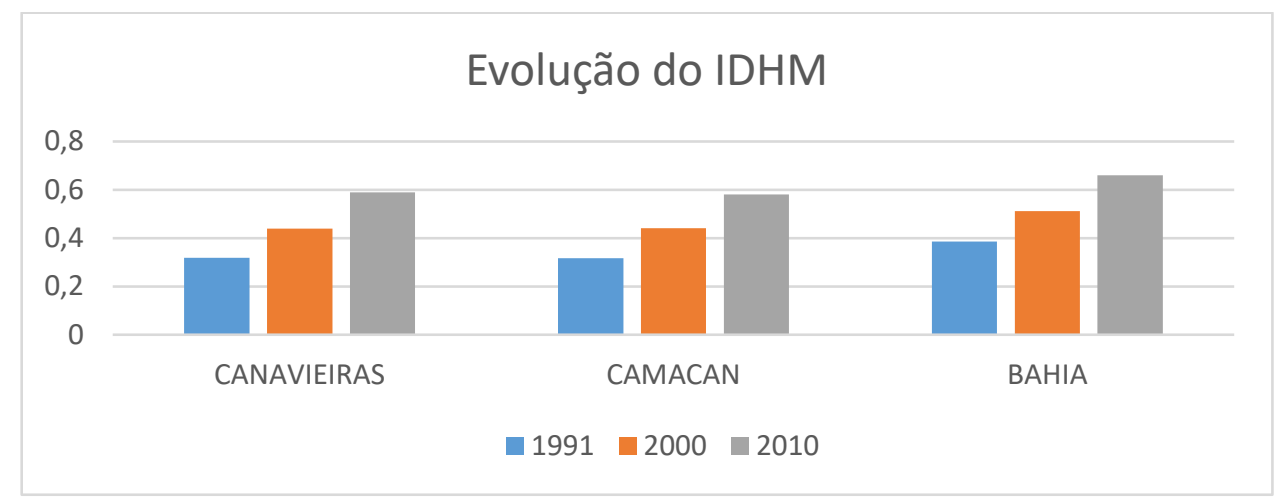

FONTE: Superintendência de Estudos Econômicos e Sociais da Bahia.

O IBGE informa para 2010 os dados que utilizamos: Camacan com 31.472 habitantes, caracterizado como "Centro Local" e Canavieiras com 32.336 habitante caracterizado como "Centro de Zona” pelo IBGE. Portanto, na hierarquia urbana do IBGE Camacan está um degrau acima. Estas cidades distam aproximadamente 100 km entre si.

Toda esta região sofreu um grande impacto a partir de 1989, com o aparecimento de uma grande praga no cultivo dos cacauais, conforme Aguiar. Canavieiras teve adicionalmente outra praga, analisada por mim em parceria com Schmidt (2009) atacando o caranguejo, crustáceo símbolo da cidade, a partir do qual se faz a Festa Nacional do Caranguejo. Esta praga, estudada como "Mortandade em massa do caranguejo Ucides cordatus" dizimou quase $90 \%$ deste recurso pesqueiro e contribuiu para desestabilizar a cadeia produtiva do caranguejo e a própria atividade turística que o utilizava como símbolo para divulgação na mídia em geral.

Acima demonstramos que embora Camacan seja um Centro Local que disponha de serviços e comércio servindo às cidades num raio de pelo menos $50 \mathrm{~km}$, sua população economicamente ativa demonstra pior qualidade de vida que Canavieiras, considerando os dados no ano de referência de 2010, quatro anos após a criação da RESEX.

A População Economicamente Ativa (PEA) das cidades analisadas já demonstra uma grande vantagem comparativa para Canavieiras, mas é o PIB de Canavieiras que mais cresce após a criação/consolidação da RESEX com percentuais sempre superiores à Bahia e ao Brasil, conforme pudemos ver no gráfico seguinte, figura 5. Fenômeno positivo também é a evolução da ocupação da PEA demonstrada na figura 4. Canavieiras 
conta com agronegócio, mas é importante lembrar que carteira assinada gera salário, não gera renda.

Devemos lembrar que no momento de criação desta UC, os setores desenvolvimentistas sempre promoveram campanhas junto a opinião pública, tentando argumentar que a população de Canavieiras estaria condenada ao fracasso e que viveria como a Tanzânia, um dos piores países africanos em termos de Índice de Desenvolvimento Humano (IDH).

Figura 4: Gráfico comparativo da PEA nos pesquisados. Municípios.

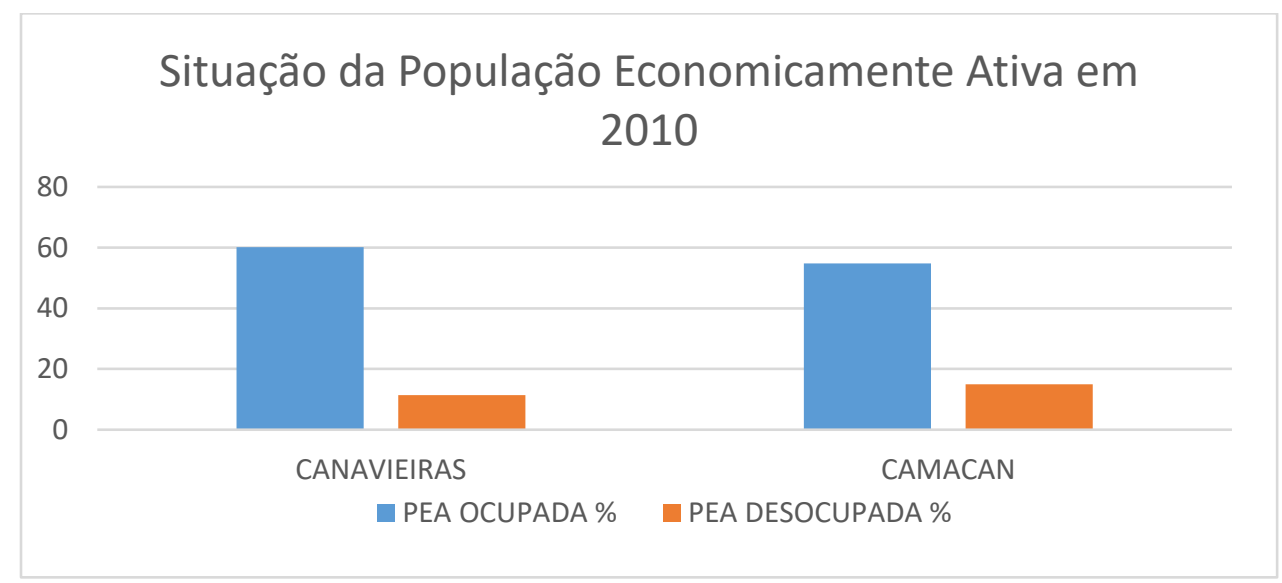

FONTE: Superintendência de Estudos Econômicos e Sociais da Bahia, 2018.

No gráfico seguinte (Figura 5) apresentamos dados que demonstram exatamento o contrário, refutando esta afirmativa, pois em uma sequência de onze anos analisados comparando dados do PIB deste município com o PIB do município de Camacan, do Estado da Bahia e com o PIB do Brasil. Nota-se que Canavieiras começou com um valor negativo no ano de 2005, mas que em oito anos desta sequência o crescimento deste indicador ultrapassa $10 \%$ ao ano, logo, muito distante de um indicador africano de desenvolvimento, aproximando-se em números relativos com os indicadores chineses que por décadas estiveram na casa dos dois dígitos. 
Figura 5. Gráfico com evolução do PIB nos municípios de Canavieiras e Camacan, juntamente com o Estado da Bahia e do Brasil.

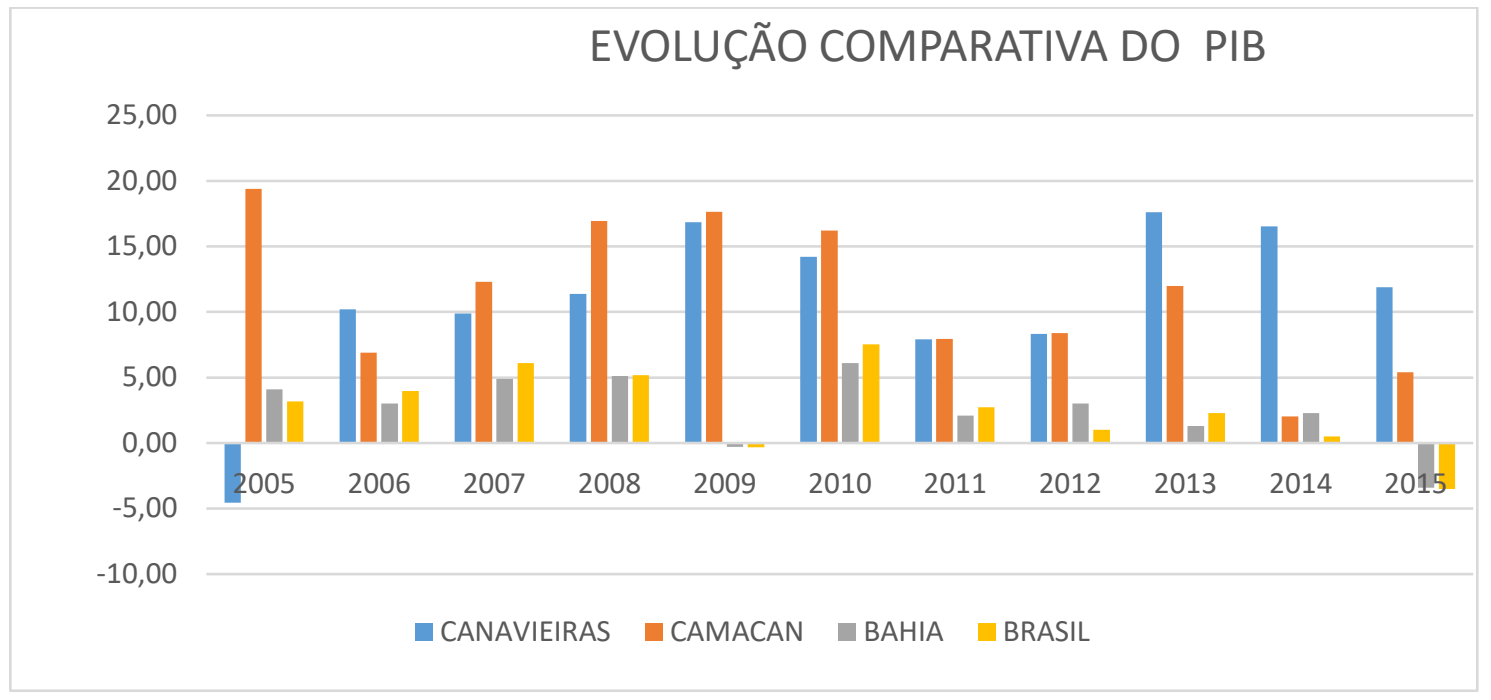

FONTE: Dados obtidos de: Jornal Gazeta do Povo, Jornal O Globo.com e SEI, 2018.

Não somente em números absolutos aconteceu melhoria em Canavieiras, pois o índice de GINI destas cidades (Tabela 1) registrou a seguinte evolução entre 2000 e 2010, o que pode ser explicado pela organicidade socioeconômica advinda pela criação da RESEX de Canavieiras, que possibilitou a estruturação na comercialização de pescados e mariscos, com a venda direta partindo agora de suas associações, incrementando ganho direto para cada família, que passa a ser beneficiada por essa nova estrutura organizacional, garantindo uma nova precificação, logística e armazenamento, que possibilitam, inclusive, a exportação de seus produtos para outras localidades. Para Lefebvre (2001, p. 58), a cidade é um nível concreto da realidade social, portanto o que ocorre nela não pode ser analisado apenas pelo pressuposto a continuidade histórica ilusória, mas que essa sofre pressões e alterações em "razão de 'processos globais' relativamente contínuos" e "em função de modificações profundas no modo de produção, nas relações 'cidade-campo', nas relações de classe e de propriedade”. 
Tabela1: Evolução do índice de GINI nos municípios de Canavieiras e Camacan.

\begin{tabular}{|l|c|c|c|}
\hline MUNICÍPIO & Ano 2000 & Ano 2010 & Percentual de avanço \\
\hline CANAVIEIRAS & 0,603 & 0,490 & $18,74 \%$ \\
\hline CAMACAN & 0,627 & 0,566 & $09,73 \%$ \\
\hline
\end{tabular}

FONTE: Superintendência de Estudos Econômicos e Sociais da Bahia.

Com base nos dados apresentados na tabela acima e no Gráfico 5, podemos compreender que aconteceu uma importante evolução econômica no município de Canavieiras, não somente no PIB, que é uma medida absoluta, mas também no índice de GINI. Dessa forma, sendo o índice de Gini um indicador que se expressa em número de zero a um em relação a situação social e tem a seguinte definição:

O Índice de Gini, criado pelo matemático italiano Conrado Gini, é um instrumento para medir o grau de concentração de renda em determinado grupo. Ele aponta a diferença entre os rendimentos dos mais pobres e dos mais ricos. Numericamente, varia de zero a um (alguns apresentam de zero a cem). O valor zero representa a situação de igualdade, ou seja, todos têm a mesma renda (WOLFFENBÜTTEL, 2004).

A cidade de Camacan, com um comércio que atende três cidades e vários povoados em um raio de $50 \mathrm{~km}$, e com indústria de confecções não pode competir com Canavieiras, a despeito do senso comum ainda considerar a indústria como maior gerador de empregos. Consideramos que o extrativismo praticado no estuário protegido por esta UC é o elemento gerador desta positiva variação do PIB e do IDHM (Tabela 2).

Tabela 2: Evolução do PIB nos municípios de Canavieiras e Camacan.

\begin{tabular}{|l|c|c|c|c|c|}
\hline \multicolumn{1}{|c|}{ MUNICÍPIO } & $\begin{array}{c}2005 \text { PIB } \\
\text { Nominal em }\end{array}$ & $\begin{array}{c}\text { 2016PIB } \\
\text { Nominal em }\end{array}$ & $\begin{array}{c}\text { Crescimento } \\
\text { do PIB }\end{array}$ & $\begin{array}{c}\text { IDHM } \\
\text { ano } \\
\text { annn }\end{array}$ & $\begin{array}{c}\text { IDHM } \\
\text { ano } \\
\text { anin }\end{array}$ \\
\hline CANAVIEIRAS & $92.654,967$ & $309.233,195$ & $233,75 \%$ & 0,439 & 0,590 \\
\hline CAMACAN & $98.574,335$ & $269.740,759$ & $173,64 \%$ & 0,441 & 0,581 \\
\hline
\end{tabular}

FONTE: Dados obtidos de: IBGE e Atlas Brasil. Obs.: PIB nominal X R\$ 1.000,00; IDHM varia de 0 a 1.

Com base na tabela acima é possível observar o maior crescimento do PIB entre os anos de 2005 a 2016. Mas, não apenas o PIB de Canavieiras ultrapassou o PIB de Camacan em 15\%. No ano de 2016 o IDHM também demonstra que Canavieiras está evoluindo positivamente do ponto de vista econômico. 


\section{CONCLUSÃO}

Tendo nascido em 6 de junho de 2006, partindo principalmente da luta e do anseio da população tradicional que sobrevive dos recursos do estuário do Rio Pardo e adjacências no município de Canavieiras, a RESEX de Canavieiras foi uma construção de luta e resistência. Resistiu a oposição de políticos e empresários conquistando soberania protegendo amplo espaço e gerando renda para as comunidades que protege e o seu entorno. Este estudo conseguiu caracterizar a resistência aos extrativistas como uma ação de cunho fundiário, com estratégias de discussão de propriedade idênticas às que ocorrem em outros espaços, a exemplo das trajetórias para criação de RESEX no litoral do Ceará.

No entanto, sendo esta Unidade de Conservação (UC) de uso sustentável, porém sem a possibilidade de propriedade privada, isso contrariou enormemente o capital especulativo, os latifundiários locais, que se utilizaram da mídia impressa na cidade produzindo "fake news" em diversas formas, para tentar anular ou reverter o processo de criação dessa UC.

A existência do conflito fundiário como o mais aparente na trajetória desta reserva e a melhoria nos indicadores econômicos com consequente aumento da qualidade de vida ficou patente, pois os dados de IDHM de Canavieiras e o índice de GINI aqui presentes evidenciam esta possibilidade, demonstrada na melhoria destes dois indicadores em Canavieiras e entorno, ainda que se compare a evolução do PIB de Canavieiras com a Bahia e o Brasil de 2005, antes da criação da UC até 2015, observamos que esta cidade registrou números maiores que $10 \%$, em sete dos 11 anos que pudemos analisar.

Consideramos assim, positiva a trajetória desta Reserva Extrativista e apelamos para novos e aprofundados estudos, que possam divulgar esta experiência e preservar esta política pública, levando em conta a preservação do meio ambiente e o desenvolvimento sustentável, gerando renda e melhoria da qualidade de vida, principalmente, das populações tradicionais secularmente nela instalada e daqueles que vivem em seu entorno, possibilitando o acesso a alimentos ainda saudáveis (predominantemente pescados) e com preços justos. 


\section{REFERÊNCIAS}

\section{AGUIAR. P. C. B. de. TRANSFORMAÇÕES SOCIOAMBIENTAIS DO}

\section{MUNICÍPIO DE CANAVIEIRAS (BAHIA): Uma análise à influência da RESEX.}

Dissertação de Mestrado UESC 2011. 112 f. Dissertação de Mestrado. Programa Regional de pós-Graduação em Desenvolvimento e Meio Ambiente. UESC - Ilhéus BA, Disponível em:

<http://www.biblioteca.uesc.br/biblioteca/bdtd/200960111D.pdf>Acesso em 21 set. 2018.

Atlas Brasil:<http://atlasbrasil.org.br/2013/pt/perfil_m/canavieiras_ba>. Acesso em 21 set. 2018.

BRASIL. Lei de Política Nacional do Meio Ambiente. Disponível em:

http://www.planalto.gov.br/CCIVIL_03/Leis/L9985.htm. Acesso em 21 de set. de 2018.

ARRUDA, R. Populações tradicionais e a proteção dos recursos naturais em unidades de conservação. Ambiente \& Sociedade 1999, (Sem mês). Disponível em:<https://www.redalyc.org/pdf/317/31713413007.pdf>Acesso em 22 de jul. de 2019.

BARDIN, L. Análise de Conteúdo. Lisboa: Ed. 70, 1977, 225p.

BRASIL. Decreto s/n., de 05 de junho de 2006. Criação da Reserva Extrativista Marinha de Canavieiras. 2006. Disponível em:<

http://www.planalto.gov.br/ccivil_03/_Ato2004-2006/2006/Dnn/Dnn10844.htm> Acesso em 21 de set. 2018.

DIAS, G. F. Educação Ambiental: Princípios e Práticas. 9º ed. São Paulo: Gaia, 2004. $541 \mathrm{p}$.

HARVEY, D.; SANTOS JÚNIOR, J. A. R. dos. A Teoria do Desenvolvimento

Desigual do Capitalismo. Oeste do Paraná. Vol. 7 N. 2. 2014.Disponível em:<http://erevista.unioeste.br/index.php/geoemquestao/article/view/8865/7621> Acesso em 22 de jul. de 2019.

\section{IBGE. INSTITUTO BRASILEIRO DE GEOGRAFIA E ESTATÍSTICA.}

Disponível em: <https://biblioteca.ibge.gov.br/biblioteca-

catalogo $?$ id=720\&view=detalhes $>$ Acesso em 22 de set. de 2018.

LIMA, M. do C. Reservas Extrativistas no Ceará: direitos, processos e resolução de conflitos. Disponível em: <http://portal.andes.org.br/imprensa/publicacoes/imp-pub1572372168.pdf>. Acesso em 22 de jul. de 2019.

MACHADO, R. A. S. Repositório Institucional UFBA. O meio natural na organização produtiva da população pesqueira tradicional do município de Canavieiras/BA. UFBA, 2007. Disponivel em:

<https://repositorio.ufba.br/ri/bitstream/ri/17814/1/Ricardo\%20Augusto\%20Souza\%20 Machado.pdf > Acesso em 04 de novembro de 2018. 
MANZOCHI, L. H.; SANSOLO, D. G. Educação, Escola e Meio Ambiente. In: SORRENTINO, M. et al. (org.). Cadernos do III Fórum de Educação Ambiental. São Paulo: GAIA, 1995.

PERRUCHO, W. Jornal TABU. Canavieiras BA. Dados pesquisados entre 2006 e 2018.

RAFFESTIN, C. Por uma Geografia do Poder. São Paulo: Ática, 1993.

RIBEIRO JUNIOR, J. A. dos S. David Harvey e a teoria do desenvolvimento geográfico desigual do capitalismo. Geografia em Questão, [S. l.], v. 7, n. 2, 2014. DOI: $10.48075 /$ geoq.v7i2.8865. Disponível em: https://erevista.unioeste.br/index.php/geoemquestao/article/view/8865. Acesso em 22 de jul. 2019.

SANTOS, M. Espaço e Método. São Paulo: Nobel, 1985. (Coleção Espaços).

SANTOS, M. A Natureza do Espaço. Técnica e Tempo. Razão e Emoção. $2^{\mathrm{a}}$ Edição. São Paulo: Hucitec, 1997.

SCHMIDT, A. J. et al. Estudo Comparativo da Dinâmica Populacional de Caranguejo Uçá, Ucides Cordatus (linnaeus, 1763) (crustacea decapodabrachyura), em Áreas Afetadas e Não Afetadas por uma Mortalidade em Massa no Sul da Bahia, brasil. Boletim Técnico Científico do CEPENE - Volume 17 - Número 1 - Ano 2009. Disponível em: <http://www.icmbio.gov.br/cepene/publicacoes/boletimtecnico-cientifico/33-volume-xvii/315-art03v17.html>. Acesso em 22 de jul. de 2019.

SEI. Superintendência de Estudos Econômicos e Sociais da Bahia. Disponível em: $<$ http://www.sei.ba.gov.br/index.php?option=com_content\&view=article\&id=2000\&Ite mid=284>. Acesso em 21 set. 2018.

SILVA, R. S.; VIANA, J. C.; ARAÚJO, S. M. "Ações Integradas para conservação, recuperação e preservação ambiental dos Manguezais de Canavieiras-BA". 2002. Processo 02006.00.2618-2001/79 IBAMA/CNPT para criação da Resex Canavieiras.

WOLFFENBÜTTEL, A. Revista Desafio do Desenvolvimento. Disponível em: <http://www.ipea.gov.br/desafios/index.php?option=com_content\&id=2048: catid= 28>Acesso em 22 de jul. de 2019.

Recebido em: 20/01/2022

Aprovado em: 21/02/2022

Publicado em: 24/02/2022 